\title{
Epidemiological characteristics and mortality risk factors among COVID-19 patients in Ardabil, Northwest of Iran
}

\author{
Davoud Adham', Shahram Habibzadeh², Hassan Ghobadi ${ }^{3}$ Shabnam Asghari Jajin', \\ Abbas Abbasi-Ghahramanloo ${ }^{1^{*}}$ and Eslam Moradi-Asl ${ }^{1 *}$ (D)
}

\begin{abstract}
Background: Coronavirus disease highly contagious, is prevalent in all age and sex groups infecting the respiratory system. The present study seeks to investigate the epidemiology and effective factors in mortality of patients with COVID-19 in Ardabil province, northwestern Iran.

Methods: In a retrospective study, the hospitalized patients with laboratory-diagnosed COVID-19 between February to August 2020 were enrolled. The data registration portal was designated according to Iranian Ministry of Health and Medical Education guidelines. In this portal, demographic information, clinical presentation, laboratory and imaging data were registered for patients in all hospitals in the same format. The Hosmer-Lemeshow strategy was used for variable selection in a multiple model.

Results: Of the patients involved 2812(50.3\%) were male and 150 (2.7\%) had contact with a confirmed case of COVID-19 in the last 14 days. Pre-existing comorbidity was reported in 1310 (23.4\%) patients. Of all patients, $477(8.5 \%)$ died due to COVID-19. the result of the multiple logistic regression model indicated that after adjusting for other factors, higher age $(O R=3.11)$, fever or chills $(O R=1.61)$, shortness of breath $(O R=1.82)$, fatigue $(O R=$ $0.71)$, headache $(\mathrm{OR}=0.64)$, runny nose $(\mathrm{OR}=1.54)$, Skeletal muscle pain $(\mathrm{OR}=1.53)$, hospitalization $(\mathrm{OR}=5.66)$, and hospitalization in ICU $(O R=5.12)$ were associated with death.

Conclusions: Hospitalization had the strongest effect on mortality followed by hospitalization in ICU, and higher age. This study showed that having some extra-pulmonary symptoms in contrast with pulmonary symptoms can predict as good prognostic factors.
\end{abstract}

Keywords: COVID-19, Extra-pulmonary, Mortality, Iran

\section{Background}

A Coronavirus is a group of single-stranded, enveloped RNA viruses with a diameter of $120-180 \mathrm{~nm}$ and is divided into four groups: Alpha, Beta, Gamma, and Delta. COVID-19 is a member of the Beta-coronavirus family $[1,2]$. This type of virus is highly contagious and infects

\footnotetext{
*Correspondence: abbasi.abbas49@yahoo.com; moradias183@yahoo.com 'Department of Public Health, School of Health, Ardabil University of Medical Sciences, Ardabil, Iran

Full list of author information is available at the end of the article
}

the respiratory system. Direct contact and respiratory droplets are the most common way of transmitting the virus in the community but other ways have also been suggested [3].

COVID-19 is associated with the demographic situation of the community. The disease is prevalent in all age and sex groups, but the highest mortality is in older men with an average age of 75 years who have a history of diseases such as cardiovascular diseases, diabetes, high blood pressure, chronic respiratory diseases, cancer,or

C C The Author(s). 2021 Open Access This article is licensed under a Creative Commons Attribution 4.0 International License, which permits use, sharing, adaptation, distribution and reproduction in any medium or format, as long as you give appropriate credit to the original author(s) and the source, provide a link to the Creative Commons licence, and indicate if changes were made. The images or other third party material in this article are included in the article's Creative Commons licence, unless indicated otherwise in a credit line to the material. If material is not included in the article's Creative Commons licence and your intended use is not permitted by statutory regulation or exceeds the permitted use, you will need to obtain permission directly from the copyright holder. To view a copy of this licence, visit http://creativecommons.org/licenses/by/4.0/. The Creative Commons Public Domain Dedication waiver (http://creativecommons.org/publicdomain/zero/1.0/) applies to the data made available in this article, unless otherwise stated in a credit line to the data. 
previous surgery $[4,5]$. According to the World Health Organization's (WHO) weekly report, as of October 4, 2020 , there have been $35,347,404$ confirmed cases of the disease of which $1,039,406$ were mortality rate the highest number it reported at 208,433 and 103,569 in the United States and India [6]. According to various studies, 18 to $33 \%$ of patients admitted to the hospital need mechanical ventilation, and up to $20 \%$ of patients are admitted to the ICU [7-10].

The most common symptoms of the disease include fever, cough, shortness of breath, fatigue, and muscle pain that are observed in most patients, and other symptoms such as diarrhea, headache and nausea have also been reported with a low percentage [11, 12]. Given that no vaccine has been successfully developed to prevent COVID-19 to date, public health measures to control the infection are necessary to limit the global spread of the virus to reduce the incidence of COVID-19. It is essential to limit travel, human-to-human transmission to reduce secondary infections in close contact with health care personnel and to prevent further spread of the disease. Many efforts have been made to slow the progression of the disease to provide or buy time for better public health care systems, a better description of COVID - 19 to guide public health advice, and timely development of diagnosis, treatment, and vaccines [1315]. With the discovery of the vaccine and the start of vaccination, it is hoped that the incidence and mortality rate of this disease will be reduced. However, it is predictable that people have some uncertainty around the details of COVID-19 vaccination. Because of some domestic reasons and lack of vaccines, adherence to protocols is still emphasized in Iran [16]. In some countries such as Iran, the death toll is still partially intermediate. This study aims to investigate the epidemiology and mortality risk factors among COVID-19 patients in Ardabil province, northwestern Iran so that by identifying these factors we can provide basic proceedings for its control and prevention.

\section{Materials and methods}

This retrospective cohort study was performed on 5587 patients in Ardabil, northwest of Iran. All patients who were admitted to the hospitals of Ardabil province from February to August 2020 were recruited for the study. During this pandemic, ten hospitals were allocated for COVID-19 in Ardabil province. All needed data were registered in the COVID-19 case registration portal at Ardabil University of Medical Sciences. The data were obtained retrospectively from this portal. The data registration portal was designated according to Iranian Ministry of Health and Medical Education guidelines. In this portal, demographic information, clinical presentation, laboratory and imaging data were registered for patients in all hospitals in the same format. The first part of this data assessed demographic information such as name, age, sex, residency place, etc. The second part evaluated information about the various clinical presentation of COVID-19 some related factors including experienced symptoms of the disease, history of contact with a confirmed case of COVID-19 in the last 14 days, the status of hospitalization, and hospitalization in ICU. The registered symptoms of COVID-19 were pulmonary symptoms such as fever or chills, cough, and shortness of breath, also, extra-pulmonary symptoms such as fatigue, sore throat, headache, runny nose, diarrhea, and skeletal muscle pain. Additionally, there was some information about the outcome of the COVID-19 and the type of treatment.

Having some preexisting chronic diseases was considered as a comorbidity in this study. These diseases were a chronic respiratory disease, cardiovascular disease, diabetes, liver disease, kidney disease, and malignancy. Atypical findings for COVID-19 on chest x-ray especially on chest CT such as an old scar, lymphadenopathy, and linear opacity does not interpret as COVID-19 imaging findings. Other abnormal findings were considered as possible signs of COVID-19.

The patients who were diagnosed with the COVID-19 according to the Iranian Ministry of Health and Medical Education guidelines have been registered in the mentioned portal. All patients with COVID-19 were eligible to enter this study and there were no exclusion criteria. The outcome was defined as death (non-survivor) or discharge (survivor). The criteria for discharge were the improvement of the general status and respiratory symptoms, absence of fever for at least 3 days, chest CT scan improvement, or at least one-time throat-swab or nasal-swab samples negative for SARS-CoV RNA assessment.

The data from all hospitals were recorded in the portal in the same format and the central office in Ardabil University of Medical Sciences had access to all recorded data anytime.

To perform simple statistical analysis, Chi-square and Fisher's exact test was used to evaluate the relationship among hospitalization, hospitalization in the ICU, and outcome of disease with the related factors. Univariate and multiple logistic regression models were run to examine the correlation among different variables and death due to COVID-19. The Hosmer-Lemeshow guidelines were used for variable selection in a multiple model [17]. $P$-value $<0.05$ was considered statistically significant.

\section{Results}

The number of all registered patients was 5586. This study indicated that the mean age of the patients was 
$52.25 \pm 20.21$ years. Of all patients, $2812(50.3 \%)$ were male and $150(2.7 \%)$ had contact with a confirmed case of COVID-19 in the last 14 days. Pre-existing morbidity was reported in 1310 (23.4\%) patients. Of all patients, 477(8.5\%) died due to COVID-19. Among all patients, 4188 (75.0\%) were hospitalized and $124(2.22 \%)$ were hospitalized in the ICU.

Table 1 shows the frequency of demographic characteristics and related factors to hospitalization, hospitalization in ICU, and the outcome of the disease. As seen in the table, hospitalization and the outcome of the disease had a significant correlation with all studied variables $(p<0.05)$. Hospitalization in ICU was significantly was correlated with age, comorbidity, the outcome of the disease, and abnormal findings in chest radiography. However, hospitalization in ICU didn't have a significant correlation with sex and previous contact with a confirmed case of COVID-19 $(p>0.05)$.

The distribution of hospitalization, hospitalization in ICU, and the outcome of the disease by the clinical presentation is illustrated in Table 2. As indicated in Table 2 hospitalization have a significant correlation with all symptoms (except diarrhea). This table also shows that hospitalization in ICU has a significant correlation with fever or chills, shortness of breath, aches and pains, runny nose, and chest pain. This table revealed that the outcome of the disease has a significant correlation with all symptoms except cough and sore throat.

In the univariate analysis, all possible effective factors were interred into the model. As can be seen in Table 3, older patients had higher odds of death. Besides, except for having cough and sore throat, all other variables were related to death. This analysis indicated that having contact with a confirmed case of COVID-19 in the last 14 days, aches and pains, headache and diarrhea have a protective effect on death but other variables increase the odds of death.

However, the result of the multiple logistic regression model indicated that after adjusting for other factors, higher age $(\mathrm{OR}=3.11)$, fever or chills $(\mathrm{OR}=1.61)$, shortness of breath $(\mathrm{OR}=1.82)$, fatigue $(\mathrm{OR}=0.71)$, headache $(\mathrm{OR}=0.64)$, runny nose $(\mathrm{OR}=1.54)$, Skeletal muscle pain $(\mathrm{OR}=1.53)$, hospitalization $(\mathrm{OR}=5.66)$, and hospitalization in ICU $(\mathrm{OR}=5.12)$ were associated with death. In other words, among these related factors, having extra-pulmonary symptoms decreased the odds of death. However other factors are related to increased odds of death due to COVID-19 in all patients.

\section{Discussion}

In this study, we reported the characteristics of all patients with COVID 19 in Ardabil province in the

Table 1 Basic characteristics of patients according to hospitalization and disease status in Ardabil province, Northwest of Iran,2020

\begin{tabular}{|c|c|c|c|c|c|c|c|}
\hline \multirow[t]{3}{*}{ Items } & \multicolumn{2}{|c|}{ Hospitalization } & \multicolumn{2}{|c|}{ Hospitalization in ICU } & \multicolumn{3}{|l|}{ Outcome } \\
\hline & Yes (\%) & $P$ value & Yes (\%) & $P$ value & Survive & Non survive & $P$ value \\
\hline & & & & & $N(\%)$ & $N(\%)$ & \\
\hline Total & $N=4188$ & & $N=124$ & & $N=5110$ & $N=477$ & \\
\hline \multicolumn{8}{|l|}{ Age groups } \\
\hline Under 50 & 1509(36.0) & $<0.001$ & $37(29.8)$ & 0.001 & $2432(47.6)$ & $79(16.6)$ & $<0.001$ \\
\hline 50 and higher & $2679(64.0)$ & & $87(70.2)$ & & $2678(52.4)$ & 398(83.4) & \\
\hline \multicolumn{8}{|l|}{ Sex } \\
\hline Male & $2017(48.2)$ & $<0.001$ & $52(41.9)$ & 0.082 & $2570(50.3)$ & 205(43.0) & 0.002 \\
\hline Female & 2171(51.8) & & $72(58.1)$ & & $2540(49.7)$ & $272(57.0)$ & \\
\hline \multicolumn{8}{|l|}{ Co morbidity } \\
\hline No & $3025(72.2)$ & $<0.001$ & $77(62.1)$ & $<0.001$ & $3962(77.5)$ & $315(66.0)$ & $<0.001$ \\
\hline Yes & 1163(27.8) & & 47(37.9) & & $1148(22.5)$ & 162(34.0) & \\
\hline \multicolumn{8}{|l|}{ Outcome } \\
\hline Survive & 3725(88.9) & $<0.001$ & $72(58.1)$ & $<0.001$ & - & - & - \\
\hline Non survive & $463(11.1)$ & & $52(41.9)$ & & - & - & \\
\hline \multicolumn{8}{|c|}{ Having contact with a confirmed case of COVID 19 in last 14 days } \\
\hline No & $4042(98.3)$ & $<0.001$ & 115(96.6) & 0.568 & 148(3.0) & $2(0.4)$ & 0.001 \\
\hline Yes & $68(1.7)$ & & $4(3.4)$ & & 4863(97.0) & 470(99.6) & \\
\hline \multicolumn{8}{|c|}{ Abnormal findings in chest radiography } \\
\hline No & $3676(87.8)$ & $<0.001$ & 103(83.1) & 0.005 & $4641(90.8)$ & $413(86.6)$ & 0.003 \\
\hline Yes & $512(12.2)$ & & $21(16.9)$ & & $469(9.2)$ & $64(13.4)$ & \\
\hline
\end{tabular}


Table 2 Clinical presentation according to the disease status in Ardabil province, Northwest of Iran,2020

\begin{tabular}{|c|c|c|c|c|c|c|c|}
\hline \multirow[t]{3}{*}{ Items } & \multicolumn{2}{|c|}{ Hospitalization } & \multicolumn{2}{|c|}{ Hospitalization in ICU } & \multicolumn{3}{|l|}{ Outcome } \\
\hline & Yes (\%) & $P$ value & Yes (\%) & $P$ value & Survive & Non survive & $P$ value \\
\hline & \multicolumn{2}{|l|}{$N=4188$} & \multicolumn{2}{|l|}{$N=124$} & $N=5110$ & \multicolumn{2}{|l|}{$N=477$} \\
\hline \multicolumn{8}{|c|}{ Fever or chills } \\
\hline No & $1732(41.4)$ & \multirow[t]{2}{*}{$<0.001$} & $46(37.1)$ & \multirow[t]{2}{*}{0.040} & 2432(47.6) & 148(31.0) & \multirow[t]{2}{*}{$<0.001$} \\
\hline Yes & $2456(58.6)$ & & $78(62.9)$ & & $2678(52.4)$ & $329(69.0)$ & \\
\hline \multicolumn{8}{|c|}{ Cough } \\
\hline No & $1059(25.3)$ & \multirow[t]{2}{*}{$<0.001$} & $41(33.1)$ & \multirow[t]{2}{*}{0.137} & $1406(27.5)$ & 114(23.9) & \multirow[t]{2}{*}{0.090} \\
\hline Yes & $3129(74.7)$ & & $83(66.9)$ & & $3704(72.5)$ & $363(76.1)$ & \\
\hline \multicolumn{8}{|c|}{ Shortness of breath } \\
\hline No & 1561(37.3) & \multirow[t]{2}{*}{$<0.001$} & $24(19.4)$ & \multirow[t]{2}{*}{$<0.001$} & 2299(45.0) & 108(22.6) & \multirow[t]{2}{*}{$<0.001$} \\
\hline Yes & $2627(62.7)$ & & $100(80.6)$ & & $2811(55.0)$ & $369(77.4)$ & \\
\hline \multicolumn{8}{|c|}{ Aches and pains } \\
\hline No & 2844(67.9) & \multirow[t]{2}{*}{$<0.001$} & $96(77.4)$ & \multirow[t]{2}{*}{0.007} & $3339(65.3)$ & $352(73.8)$ & \multirow[t]{2}{*}{$<0.001$} \\
\hline Yes & $1344(32.1)$ & & $28(22.6)$ & & $1771(34.7)$ & $125(26.2)$ & \\
\hline \multicolumn{8}{|c|}{ Sore throat } \\
\hline No & 2463(58.8) & \multirow[t]{2}{*}{$<0.001$} & $69(55.6)$ & \multirow[t]{2}{*}{0.712} & $2938(57.5)$ & $262(54.9)$ & \multirow[t]{2}{*}{0.278} \\
\hline Yes & $1725(41.2)$ & & $55(44.4)$ & & $2172(42.5)$ & $215(45.1)$ & \\
\hline \multicolumn{8}{|c|}{ Headache } \\
\hline No & $3460(82.6)$ & \multirow[t]{2}{*}{$<0.001$} & 109(87.9) & \multirow[t]{2}{*}{0.055} & $4120(80.6)$ & 419(87.8) & $<0.001$ \\
\hline Yes & $728(17.4)$ & & $15(12.1)$ & & $990(19.4)$ & $58(12.2)$ & \\
\hline Runny & & & & & & & \\
\hline No & $3964(94.5)$ & 0.006 & $110(88.7)$ & 0.001 & 4885(95.6) & $429(89.9)$ & $<0.001$ \\
\hline Yes & $224(5.3)$ & & $14(11.3)$ & & $225(4.4)$ & $48(10.1)$ & \\
\hline Diarrhe & & & & & & & \\
\hline No & 4018(95.9) & 0.130 & 120(96.8) & 0.552 & $4881(95.5)$ & 466(97.7) & 0.025 \\
\hline Yes & $170(4.1)$ & & $4(3.2)$ & & $229(4.5)$ & $11(2.3)$ & \\
\hline Chest & & & & & & & \\
\hline No & $3870(92.4)$ & $<0.001$ & $95(76.6)$ & $<0.001$ & 4792(93.8) & $413(86.6)$ & $<0.001$ \\
\hline Yes & $318(7.6)$ & & $29(23.4)$ & & $318(6.2)$ & $64(13.4)$ & \\
\hline
\end{tabular}

northwest of Iran. The clinical characteristics of these patients showed that age (50-year-old and higher), hospitalization, and hospitalization in ICU were the most important risk factors for death.

The present study also indicated that there is no gender difference in the prevalence of COVID-19. However, of deceased patients most of them were female. Some studies have reported a greater prevalence of COVID-19 in males $[16,18,19]$. A study conducted in Iran showed that males are at higher risk of mortality [20]. But, gender differences seem to have less importance as a prognostic factor for death compared to age [19]. Some studies also have indicated that the susceptibility of older males is higher than older females [21]. Anyway, in this study male gender didn't have a significant effect on the death of patients in the final adjusted regression logistic model.
Several studies have indicated that comorbidities are one the strongest predictors of death or severe COVID19 [22-24]. Another study from Iran showed that having comorbidities had a significant effect on mortality [20]. Our findings showed that having any comorbidity was associated with hospitalization, hospitalization in ICU, and outcome of the disease. Also, in univariate analysis comorbidity increased the odds of death. However, this association didn't remain significant in the final model. Further investigations are needed to assess the role of comorbidities on the mortality of COVID 19 in Iran.

Pulmonary symptoms such as cough and shortness of breath were to be the most common symptom among hospitalized patients. We found that fever or chills, shortness of breath, fatigue, headache, runny nose, diarrhea, and Skeletal muscle pain were factors independently associated with mortality when adjusted for other 
Table 3 Related factors associated with death due to COVID 19 in Ardabil province, Northwest of Iran,2020

\begin{tabular}{|c|c|c|c|c|c|c|}
\hline \multirow[b]{3}{*}{ Variables } & \multicolumn{6}{|c|}{ Death due to COVID 19} \\
\hline & \multicolumn{3}{|c|}{ Crude estimation } & \multicolumn{3}{|c|}{ Adjusted estimation } \\
\hline & OR & $95 \% \mathrm{Cl}$ & $\mathbf{P}$ & OR & $95 \% \mathrm{Cl}$ & $\mathbf{P}$ \\
\hline Age (50 years old or higher) & 4.57 & $3.57-5.86$ & $<0.001$ & 3.11 & $2.39-4.06$ & $<0.001$ \\
\hline Sex (being male) & 1.34 & $1.11-1.62$ & 0.002 & 1.20 & $0.98-1.47$ & 0.072 \\
\hline Co-morbidity & 1.77 & $1.45-2.17$ & $<0.001$ & 1.25 & $1.00-1.56$ & 0.055 \\
\hline Having contact with a confirmed case of COVID 19 in last 14 days & 0.14 & $0.03-0.57$ & 0.006 & 0.290 & $0.07-1.22$ & 0.091 \\
\hline Having abnormal findings in chest radiography & 1.53 & $1.16-2.03$ & 0.003 & 1.00 & $0.74-1.35$ & 0.996 \\
\hline Fever or chills & 2.02 & $1.65-2.47$ & $<0.001$ & 1.61 & $1.29-2.02$ & $<0.001$ \\
\hline Cough & 1.21 & $0.97-1.50$ & 0.090 & 0.91 & $0.71-1.17$ & 0.463 \\
\hline Shortness of breath & 2.79 & $2.24-3.49$ & $<0.001$ & 1.82 & $1.44-2.31$ & $<0.001$ \\
\hline Aches and pains & 0.67 & $0.54-0.83$ & $<0.001$ & 0.71 & $0.57-0.89$ & 0.003 \\
\hline Sore throat & 1.11 & $0.92-1.34$ & 0.278 & - & - & - \\
\hline Headache & 0.58 & $0.43-0.76$ & $<0.001$ & 0.64 & $0.47-0.86$ & 0.004 \\
\hline Runny nose & 2.43 & $1.75-3.37$ & $<0.001$ & 1.54 & $1.06-2.24$ & 0.022 \\
\hline Diarrhea & 0.50 & $0.27-0.93$ & 0.028 & 0.66 & $0.35-1.26$ & 0.206 \\
\hline Chest pain & 2.33 & $1.75-3.11$ & $<0.001$ & 1.53 & $1.10-2.13$ & 0.011 \\
\hline Hospitalization & 12.28 & 7.19-20.99 & $<0.001$ & 5.66 & $3.28-9.78$ & $<0.001$ \\
\hline Hospitalization in ICU & 8.56 & $5.91-12.39$ & $<0.001$ & 5.12 & $3.40-7.71$ & $<0.001$ \\
\hline
\end{tabular}

variables. Among these symptoms, shortness of breath had the strongest effect on death. Some studies reported other frequencies for disease symptoms. For example among Italian and Spanish patients fever was reported as the most common symptom [19, 25]. Probably there are complex interactions between symptoms of COVID19 and other independent variables like age and gender. Identifying such a complex relationship among independent variables may help to determine the portion of each symptom in death.

Our findings revealed that hospitalizing and hospitalization in ICU increased the odds of death among all patients. In line with our results, a study from Mexico reported that hospitalization $(\mathrm{OR}=5.02)$ and hospitalization in ICU $(\mathrm{OR}=1.79)$ were associated with death [26]. This could happen due to the condition of patients at admission time. Patients with severe and critical conditions are more likely to be hospitalized or hospitalized in ICU, resulting in high inhospital mortality.

The strength of this study was its large sample that increases the generality of the findings. However, it had some limitations, too. One of these limitations was using self-reported information about some aspects of COVID-19 such as symptoms and history of contact with confirmed COVID-19. Additionally, this study was unable to explain the causal relationship between independent variables and death due to COVID-19. Some unknown factors and possible biases could distort the findings.

\section{Conclusion}

This study revealed that most of the COVID-19 deceased patients were older than 50 years old. Hospitalization had the strongest effect on mortality followed by hospitalization in ICU, and higher age. This study showed that having extra-pulmonary symptoms like skeletal muscle pain, fatigue, and headache can serve as good prognostic factors for mortality. This study showed that having some pulmonary symptoms in contrast with extra-pulmonary symptoms can predict poor prognostic factors of mortality.

\section{Abbreviations}

COVID-19: Coronavirus Disease 2019; OR: odds ratio; ICU: Intensive Care Unit; RNA: ribonucleic acid; WHO: World Health Organization; SARS-CoV: Severe acute respiratory syndrome coronavirus 2

\section{Acknowledgements}

The authors thank Ardabil Health Central and all hospitals staff for enabling this study.

\section{Authors' contributions}

AAG,SHH and EMA: Study design, Data analysis, Writing - original draft, Writing - review \& editing. DA, SAG AAG, EMA: Writing - review \& editing. EMA,HG and AAG: Data collection. The author(s) read and approved the final manuscript.

\section{Funding}

This research was supported by a grant from Ardabil University of Medical Sciences (project No: 3899).

\section{Availability of data and materials}

The datasets generated and/or analysed during the current study are not publicly available due Ethics Committee of Ardabil University of Medical Sciences restrictions but are available from the corresponding author on reasonable request. 


\section{Declarations}

\section{Ethics approval and consent to participate}

The study was approved by the Ethics Committee of Ardabil University of Medical Sciences (IR.ARUMS.REC.1399.096). Permission to conduct the study was obtained from this committee and all patients had signed an informed consent form

\section{Consent for publication}

Not applicable.

\section{Competing interests}

The authors declare no conflict of interest.

\section{Author details}

'Department of Public Health, School of Health, Ardabil University of Medical Sciences, Ardabil, Iran. ${ }^{2}$ Department of Infection Diseases, Faculty of Medicine, Ardabil University of Medical Sciences, Ardabil, Iran. ${ }^{3}$ Department of Internal Medicine, Pulmonary Division, Faculty of Medicine, Ardabil University of Medical Sciences, Ardabil, Iran.

Received: 16 December 2020 Accepted: 25 May 2021

Published online: 02 June 2021

\section{References}

1. Chan JF-W, To KK-W, Tse H, Jin D-Y, Yuen K-Y. Interspecies transmission and emergence of novel viruses: lessons from bats and birds. Trends Microbiol. 2013;21(10):544-55. https://doi.org/10.1016/j.tim.2013.05.005.

2. He J, Tao H, Yan Y, Huang S-Y, Xiao Y. Molecular mechanism of evolution and human infection with the novel coronavirus (2019-nCoV). Viruses. 2020; 12(4):428. https://doi.org/10.3390/v12040428.

3. Zhou P, Yang X-L, Wang X-G, Hu B, Zhang L. Zhang W, et al. A pneumonia outbreak associated with a new coronavirus of probable bat origin nature. 2020;579(7798):270-3. https://doi.org/10.1038/s41586-020-2012-7.

4. Boccia S, Ricciardi W, loannidis JP. What other countries can learn from Italy during the COVID-19 pandemic. JAMA Intern Med. 2020;180(7):927-8. https://doi.org/10.1001/jamainternmed.2020.1447.

5. Lai C-C, Liu YH, Wang C-Y, Wang Y-H, Hsueh S-C, Yen M-Y, et al. Asymptomatic carrier state, acute respiratory disease, and pneumonia due to severe acute respiratory syndrome coronavirus 2 (SARSCoV-2): facts and myths. J Microbiol Immunol Infect. 2020;53(3):402-12.

6. Organization WH. Coronavirus disease ( COVID-19): weekly epidemiological update1. 2020;1

7. Richardson S, Hirsch JS, Narasimhan M, Crawford JM, McGinn T, Davidson KW, et al. Presenting characteristics, comorbidities, and outcomes among 5700 patients hospitalized with COVID-19 in the new York City area. Jama. 2020;323(20):2052-9. https://doi.org/10.1001/jama.2020.6775.

8. Gold JA. Characteristics and clinical outcomes of adult patients hospitalized with COVID-19-Georgia, march 2020. MMWR Morb Mortal Wkly Rep. 2020; 69(18):545-50. https://doi.org/10.15585/mmwr.mm6918e1.

9. Goyal P, Choi JJ, Pinheiro LC, Schenck EJ, Chen R, Jabri A, et al. Clinical characteristics of Covid-19 in New York city. N Engl J Med. 2020;382(24): 2372-4. https://doi.org/10.1056/NEJMc2010419.

10. Cummings MJ, Baldwin MR, Abrams D, Jacobson SD, Meyer BJ, Balough EM, et al. Epidemiology, clinical course, and outcomes of critically ill adults with COVID-19 in new York City: a prospective cohort study. Lancet. 2020; 395(10239):1763-70. https://doi.org/10.1016/S0140-6736(20)31189-2.

11. Huang C, Wang Y, Li X, Ren L, Zhao J, Hu Y, et al. Clinical features of patients infected with 2019 novel coronavirus in Wuhan. China The lancet. 2020;395(10223):497-506. https://doi.org/10.1016/S0140-6736(20)30183-5.

12. W-j G, Z-y N. Hu Y, Liang W-h, Ou C-q, He J-x, et al. clinical characteristics of 2019 novel coronavirus infection in China. MedRxiv. 2020;382:1708-20.

13. Xu Z, Peng C, Shi Y, Zhu Z, Mu K, Wang X, et al. Nelfinavir was predicted to be a potential inhibitor of 2019-nCov main protease by an integrative approach combining homology modelling, molecular docking and binding free energy calculation. bioRxiv 2020 101101/20200127921627. 2020

14. Tai DY. Pharmacologic treatment of SARS: current knowledge and recommendations. ANNALS-ACADEMY OF MEDICINE SINGAPORE. 2007; 36(6):438.
15. Chu C, Cheng V, Hung I, Wong M, Chan K, Chan K, et al. Role of lopinavir/ ritonavir in the treatment of SARS: initial virological and clinical findings. Thorax. 2004;59(3):252-6. https://doi.org/10.1136/thorax.2003.012658.

16. Wang D, Hu B, Hu C, Zhu F, Liu X, Zhang J, et al. Clinical characteristics of 138 hospitalized patients with 2019 novel coronavirus-infected pneumonia in Wuhan. China Jama. 2020;323(11):1061-9. https://doi.org/10.1001/jama.2 020.1585

17. Jewell NP. Statistics for epidemiology: CRC press; 2003. https://doi.org/10.12 01/9781482286014.

18. Chang D, Lin M, Wei L, Xie L, Zhu G, Cruz CSD, et al. Epidemiologic and clinical characteristics of novel coronavirus infections involving 13 patients outside Wuhan. China. Jama. 2020;323(11):1092-3. https://doi.org/10.1001/ja ma.2020.1623.

19. Biagi A, Rossi L, Malagoli A, Zanni A, Sticozzi C, Comastri G, et al. Clinical and epidemiological characteristics of 320 deceased Covid-19 patients in an Italian Province: a retrospective observational study. J Med Virol. 2020;92(11): 2718-24. https://doi.org/10.1002/jmv.26147.

20. Nikpouraghdam M, Farahani AJ, Alishiri G, Heydari S, Ebrahimnia M, Samadinia $\mathrm{H}$, et al. Epidemiological characteristics of coronavirus disease 2019 (COVID-19) patients in IRAN: a single center study. J Clin Virol. 2020; 127:104378. https://doi.org/10.1016/j.jcv.2020.104378.

21. Yang $X, Y u Y, X u$ J, Shu $H$, Liu H, Wu Y, et al. Clinical course and outcomes of critically ill patients with SARS-CoV-2 pneumonia in Wuhan, China: a single-centered, retrospective, observational study. Lancet Respir Med. 2020; 8(5):475-81. https://doi.org/10.1016/S2213-2600(20)30079-5.

22. Chen $R$, Liang $W$, Jiang $M$, Guan W, Zhan C, Wang T, et al. Risk factors of fatal outcome in hospitalized subjects with coronavirus disease 2019 from a nationwide analysis in China. Chest. 2020;158(1):97-105. https://doi.org/10.1 016/j.chest.2020.04.010

23. Li X, Xu S, Yu M, Wang K, Tao Y, Zhou Y, et al. Risk factors for severity and mortality in adult COVID-19 inpatients in Wuhan. J Allergy Clin Immunol. 2020;146(1):110-8. https://doi.org/10.1016/j.jaci.2020.04.006

24. Sepandi M, Taghdir M, Alimohamadi Y, Afrashteh S, Hosamirudsari H. Factors associated with mortality in COVID-19 patients: a systematic review and meta-analysis. Iran J Public Health. 2020;49(7):1211-21. https://doi.org/1 0.18502/ijph.v49i7.3574.

25. Iftime S, López-Azcona AF, Vicente-Miralles M, Descarrega-Reina $R$ Hernández-Aguilera A, Riu F, et al. Risk factors associated with mortality in hospitalized patients with SARS-CoV-2 infection. A prospective, longitudinal, unicenter study in Reus, Spain. PloS one. 2020;15(9):e0234452.

26. Carrillo-Vega MF, Salinas-Escudero G, Garcia-Peña C, Gutierrez-Robledo LM Parra-Rodriguez L. Early estimation of the risk factors for hospitalisation and mortality by COVID-19 in Mexico. PLoS One. 2020;15(10):e0240394.

\section{Publisher's Note}

Springer Nature remains neutral with regard to jurisdictional claims in published maps and institutional affiliations.

Ready to submit your research? Choose BMC and benefit from:

- fast, convenient online submission

- thorough peer review by experienced researchers in your field

- rapid publication on acceptance

- support for research data, including large and complex data types

- gold Open Access which fosters wider collaboration and increased citations

- maximum visibility for your research: over $100 \mathrm{M}$ website views per year

At BMC, research is always in progress.

Learn more biomedcentral.com/submissions 